\title{
PENGARUH PENDIDIKAN KESEHATAN TERHADAP PERILAKU \\ HIDUP BERSIH DAN SEHAT PADA PEMULUNG \\ DI TPA WONOKROMO-SURABAYA \\ Erika Untari Dewi \\ untarierika@yahoo.co.id
}

\begin{abstract}
Essentially, health education is a wish or an effort to deliver health message to society, group or individual in order to improve healthy lifestyle behaviors. Aim of this research is to know influence of health education to healthy lifestyle behaviors on scavengers at TPA Wonokromo Surabaya. This research used pre experiment design by using one group pre-post test design. Population of the research was 20 respondents who are scavengers at TPA Wonokromo Surabaya. 19 of 20 respondents were sampled using simple random sampling. Data collection used questionnaire before and after participating in health education about healthy lifestyle behaviors. Then the data was tested using wilcoxon test. Result of the research indicated that most respondents have less behavior (11 or 57.89\%) before participating in health education and after participating in health education there are 14 or $73.86 \%$ who have good behavior and statistical result indicated that $p=0.000$. It means there is influence of health education to healthy lifestyle behaviors on scavengers at TPA. Wonokromo Surabaya. Therefore, health education on healthy lifestyle behavior can be enhanced to make good healthy lifestyle behaviors.
\end{abstract}

Keywords: health education, healthy lifestyle behavior

\begin{abstract}
ABSTRAK.
Pendidikan kesehatan pada hakikatnya adalah suatu kegiatan atau usaha untuk menyampaikan pesan kesehatan kepada masyarakat, kelompok atau individu guna meningkatkan perilaku hidup bersih dan sehat (PHBS). Tujuan penelitian ini adalah untuk mengetahui Pengaruh Pendidikan Kesehatan Terhadap Perilaku Hidup Bersih Dan Sehat Pada Pemulung Di TPA Wonokromo Surabaya. Penelitian ini menggunakan desain penelitian Pra-Eksperimen dengan menggunakan one group pra-post test design, populasi pada penelitian ini sebanyak 20 responden yaitu semua pemulung yang berada disekitar TPA Wonokromo Surabaya dan sampel yang diambil adalah 19 responden dengan menggunakan Simple Random Sampling. Pengumpulan data menggunakan lembar kuisioner sebelum dan setelah dilakukan pendidikan kesehatan tentang perilaku hidup bersih dan sehat, kemudian diuji dengan menggunakan uji Wilcoxon. Dari hasil penelitian menunjukkan bahwa sebagian besar responden memiliki perilaku kurang sebanyak 11 orang $(57,89 \%)$ sebelum dilakukannya pendidikan kesehatan dan setelah dilakukan pendidikan kesehatan yang berperilaku baik sebanyak 14 orang $(73,68 \%)$ dan berdasarkan hasil statistik didapatkan $\mathrm{p}=0,000$ yang berarti ada Pengaruh Pendidikan Kesehatan Terhadap Perilaku Hidup Bersih Dan Sehat Pada Pemulung Di TPA Wononkromo Surabaya. Dengan ini pendidikan kesehatan tentang perilaku hidup bersih dan sehat dapat ditingkatkan untuk mengubah perilaku hidup sehat ke arah yang lebih baik.
\end{abstract}

Kata kunci : Pendidikan Kesehatan, Perilaku Hidup Bersih dan Sehat 


\section{Pendahuluan}

Setiap manusia yang hidup di dunia ini memerlukan lingkungan yang bersih dan sehat agar dapat memberikan kenyamanan hidup, oleh karena itu, manusia wajib peduli terhadap lingkungan dengan cara menjaga, memelihara dan menciptakan lingkungan hidup yang baik. Kepedulian manusia terhadap lingkungan bisa terlihat dari respons seseorang terhadap lingkungan sebagai determinan kesehatan manusia. Banyak cara yang dapat dilakukan untuk mendapat ilmu dan pengetahuan untuk hidup sehat, salah satunya melalui pendidikan. Pendidikan kesehatan pada hakikatnya adalah suatu kegiatan atau usaha untuk menyampaikan pesan kesehatan pada masyarakat, kelompok, atau individu, dengan harapan bahwa dengan adanya pesan tersebut masyarakat, kelompok atau individu dapat memperoleh pengetahuan tentang kesehatan yang lebih baik (Soekidjo, Notoatmodjo,1997). Setiap individu perlu mengetahui perilaku hidup bersih dan sehat dalam penerapannya di kehidupan seharihari. Perilaku hidup bersih dan sehat (PHBS) adalah melakukan kebiasaan-kebiasaan hidup yang bersih dan sehat serta menghindarkan kebiasaan-kebiasaan yang buruk dan tidak sehat. Tujuan PHBS adalah meningkatkan pengetahuan, kesadaran, kemauan dan kemampuan masyarakat agar hidup bersih dan sehat serta masyarakat termasuk swasta dan dunia usaha berperan serta aktif mewujudkan derajat kesehatan yang optimal. Peningkatan PHBS tersebut dilaksanakan melalui 5 tatanan, diantaranya adalah tatanan rumah tangga. Terdapat 10 indikator PHBS tatanan rumah tangga, yaitu pertolongan persalinan oleh tenaga kesehatan, bayi diberi ASI ekslusif, mempunyai jaminan pemeliharaan kesehatan, ketersediaan air bersih, ketersediaan jamban sehat, kesesuaian luas lantai dengan jumlah penghuni, lantai rumah bukan lantai tanah, tidak merokok di dalam rumah, melakukan aktifitas fisik setiap hari, dan makan buah dan sayur setiap hari. Keberhasilan program PHBS tatanan rumah tangga didasarkan kepada 10 indikator yang dibagi menjadi 4 tingkatan atau kategori: Sehat I, Sehat II, Sehat III, dan Sehat IV, dengan target pemerintah yaitu tercapainya penduduk Indonesia yang ber-PHBS pada tingkat Sehat IV (Depkes RI, 2006). ). Apabila tidak diimbangi dengan penerapan perilaku hidup bersih dan sehat (PHBS), maka bisa di pastikan generasi-generasi muda akan terpapar oleh beragam penyakit, yang mungkin bisa membahayakan kelangsungan hidup manusia di muka bumi ini. Pemulung merupakan salah satu sasaran tepat untuk menerapkan PHBS sedari dini.

Berdasarkan hasil pengamatan di lingkungan pemukiman TPA WonokromoSurabaya yang mayoritas adalah pemulung dapat dilihat bahwa pengetahuan masyarakat belum mengerti betul mengenai pola hidup bersih dan sehat (PHBS), dibuktikan dengan kondisi lingkungan yang kumuh dan pencahayaan yang kurang terhadap tempat tinggal. Walaupun dengan melihat kondisi rumah yang memiliki fasilitas seperti jamban pribadi dan tingkat ekonomi yang cukup mampu namun perilaku untuk hidup bersih dan sehat mereka belum tampak. Hal ini dibuktikan saat ditanya "menurut ibu menguras bak mandi atau tempat penampungan air berapa kali dalam seminggu, klien menjawab sekurangkurangnya 1 bulan. Mendengar pernyataan ini cukup membuktikan bahwa pengetahuan keluarga mengenai PHBS masih kurang sehingga perlu dilakukannya pendidikan kesehatan mengenai perilaku hidup bersih dan sehat (PHBS) untuk mengubah perilaku keluarga ke arah yang lebih sehat. Para pemulung yang berada di sekitar TPA terbagi dalam dua kelompok yaitu pemulung yang memiliki rumah sendiri dan pemulung yang bertempat tinggal di dalam daerah TPA dengan bangunan seadanya. Perbedaan dari kedua kelompok tersebut dilihat dari tersedianya sarana atau fasilatas seperti air bersih, jamban dan lain sebagainya. Pemulung yang memiliki fasilitas tersebut belum tampak atau terlihat sudah menerapkan perilaku hidup bersih dan sehat. Dengan keadaan atau kondisi seperti ini cukup mengungkapkan bahwa pengetahuan masyarakat di sekitar TPA mengenai PHBS masing kurang.

Dampak yang terjadi bila program PHBS tidak dilakukan atau diterapkan dalam masyarakat dapat mengakibatkan besarnya jumlah masyarakat yang terpapar penyakit akan meningkat.

Permasalahan seperti ini pemerintah perlu bekerja sama dengan pihak kesehatan untuk mensosialisasikan masalah-masalah 
kesehatan kepada masyarakat secara intensif dan berkala, salah satunya bisa dilakukan melalui pendidikan kesehatan terhadap masyarakat. Peranan pendidikan kesehatan adalah melakukan intervensi faktor perilaku sehingga perilaku individu, kelompok atau masyarakat sesuai dengan nilai-nilai kesehatan dan dapat dilakukan melalui promosi kesehatan (Health promotion). Program pendidikan kesehatan, disamping melakukan evaluasi juga dilakukan monitoring atau pemantauan program dengan tujuan agar berjalan sesuai dengan yang direncanakan, baik waktunya maupun jenis kegiatannya. Perhatian khusus perlu diberikan pada kelompok beresiko seperti masyarakat yang tinggal di sekitar TPA agar derajat kesehatannya tidak memburuk dan tetap hidup produktif. Dari kajian ini tentunya dapat diharapkan diperolehnya suatu cara preventif dalam pekerjaan mereka untuk melindungi dari penyakit yang berkepanjangan sehingga tidak merugikan kesehatan para pemulung. Banyaknya permasalahan kesehatan pada pemulung menggambarkan kurangnya pengetahuan mereka mengenai pola hidup bersih dan sehat terhadap profesi pekerjaannya. menanggapi latar belakang diatas, maka perlu dilakukan penelitian guna mengetahui pengaruh pendidikan kesehatan terhadap pola hidup bersih dan sehat.

\section{Metode}

$\begin{array}{ccc}\begin{array}{c}\text { Peneliti } \\ \text { penelitian }\end{array} & \begin{array}{c}\text { menggunakan } \\ \text { pra-eksperimen }\end{array} & \begin{array}{r}\text { desain } \\ \text { dengan }\end{array}\end{array}$ pendekatan one group pra-post test design. Rancangan one group pra-post test design adalah mengungkapkan hubungan sebab akibat dengan cara melibatkan satu kelompok subjek. Kelompok subjek diobservasi sebelum dilakukan intervensi, kemudian diobservasi lagi setelah intervensi. Tujuan peneliti menggunakan desain ini adalah agar peneliti dapat menilai pengaruh pendidikan kesehatan terhadap perilaku hidup bersih dan sehat pada pemulung di TPA pada kelompok pra dan kelompok post pendidikan sebelum dan sesudah intervensi.

Variabel bebas dalam penelitian ini adalah pendidikan kesehatan pada pemulung di TPA. Variabel terikat pada penelitian ini adalah pola hidup bersih dan sehat pada pemulung di TPA. Pada penelitian ini populasinya adalah semua pemulung yang berada disekitar TPA Wonokromo-Surabaya. Pada pertemuan pertama akan dibagi kuesioner mengenai PHBS untuk mengkaji perilaku hidup bersih dan sehat (PHBS), dilanjutkan pemberian pendidikan kesehatan baik secara individual maupun kelompok (melihat situasi dan kondisi tempat penelitian). Pada pertemuan terakhir 2 minggu kemudian dibagikan kuesioner untuk mengkaji adakah perubahan pengetahuan yang terjadi setelah diberikan pendidikan kesehatan. Peneliti mengadakan pendekatan kepada responden untuk mendapatkan persetujuan sebagai responden dan menerima responden yang sesuai dengan kriteria penelitian, responden dipilih menggunakan probability sampling dimana setiap individu dalam populasi mempunyai kesempatan untuk terpilih atau tidak terpilih sebagai sampel. Sampling yang digunakan yaitu simple random sampling dimana nama responden ditulis pada secarik kertas, diletakkan dikotak, diaduk dan diambil secara acak. Satu nama yang keluar dari kotak tidak dipiih sebagai responden. Reponden yang terpilih berjumlah 19 orang diberi kuisioner dan diminta untuk mengisi kuisioner.

Analisa data yang digunakan dalam penelitian ini yaitu SPSS 16 yang menggunakan Uji Wilcoxon test. Uji Wilcoxon merupakan pengembangan dari Uji $\mathrm{t}$ dengan ketelitian hasil analisis Wilcoxon dibandingkan Uji $t$ adalah tidak hanya dapat menunjukkan arah perbedaan tetapi juga dapat menunjukkan perbedaan antara kelompok - kelompok yang dibandingkan. Uji peringkat bertanda Wilcoxon digunakan jika besaran maupun arah perbedaan relevan untuk menentukan apakah terdapat pebedaan yang sesungguhnya antara data yang satu dengan data yang lainnya. Menentukan pengaruh variabel bebas dalam penelitian ini adalah pendidikan kesehatan terhadap variabel terikat dalam penelitian ini adalah perilaku hidup bersih dan sehat (PHBS). Penelitian ini menggunakan dua variabel berskala ordinal dan menguji tentang Pengaruh Pendidikan Kesehatan Terhadap Perilaku Hidup Bersih dan Sehat sehingga dalam penelitian ini penulis menggunakan uji Wilcoxon test. Pada uji Wilcoxon test bila Jika statistik hitung lebih kecil atau sama dengan nilai kritis, maka hipotesis nol ditolak. Nilai test statistik lebih besar dari 
nilai kritis, maka Ho tidak ditolak yang diinformasikan dalam bentuk presentasi dan narasi.

\section{Hasil}

Lokasi penelitian dilakukan di TPA Wonokromo terletak di jalan Gunung Sari. TPA Wonokromo berada di lingkungan kecamatan Wonokromo-Surabaya. Sebelah utara terdapat Terminal Joyoboyo, sebelah timur berbatasan dengan kali Rola, Sebelah barat berbatasan dengan Pertamina, dan sebelah selatan berbatasan dengan Jl. Gunung Sari. Ada pula kegiatan yang selalu diadakan oleh komunitas pemulung di TPA Wonokromo adalah dengan mengikuti pertemuan setiap bulan bersama dinas kebersihan untuk membahas mengenai kebersihan lingkungan sepanjang bantaran sungai yang diwakili oleh kordinator dari pemulung tersebut. Fasilitas yang terdapat di TPA Wonokromo berupa hunian bagi masyarakat bantaran sungai yang di bangun oleh pemerintah dan sudah di lengkapi dengan sarana dan prasarana lain seperti toilet dan kamar mandi dimana sebagian dari pemulung tinggal ditempat tersebut.

Tabel 1 Karakteristik responden berdasarkan umur April 2014 di TPA Wonokromo

\begin{tabular}{|c|c|c|}
\hline Umur & Jumlah & $\begin{array}{c}\text { Prosentase } \\
(\mathbf{\%})\end{array}$ \\
\hline$<20$ tahun & 2 & 10,52 \\
\hline $20-30$ tahun & 2 & 10,52 \\
\hline $31-40$ tahun & 4 & 21,05 \\
\hline$>40$ tahun & 11 & 57,89 \\
\hline Total & 19 & 100 \\
\hline
\end{tabular}

Tabel 2 Karaktristik responden berdasarkan jenis kelamin April 2014 di TPA Wonokromo

\begin{tabular}{|c|c|c|}
\hline $\begin{array}{c}\text { Jenis } \\
\text { Kelamin }\end{array}$ & Jumlah & $\begin{array}{c}\text { Prosentase } \\
(\boldsymbol{\%})\end{array}$ \\
\hline Laki - laki & 19 & 100 \\
\hline Perempuan & 0 & - \\
\hline Total & 19 & 100 \\
\hline
\end{tabular}

\section{Pembahasan}

Berdasarkan tabel 4 terlihat bahwa dari 19 responden, 11 orang diantaranya berprilaku kurang $(57,89 \%)$, hal ini berarti kesadaran dari para pemulung tentang hidup
Tabel 3 Karaktristik responden berdasarkan pendidikan April 2014 di TPA Wonokromo

\begin{tabular}{|c|c|c|}
\hline Pendidikan & Jumlah & $\begin{array}{c}\text { Prosentase } \\
(\boldsymbol{\%})\end{array}$ \\
\hline Tidak Sekolah & 3 & 15,78 \\
\hline SD & 6 & 31,57 \\
\hline SMP & 8 & 42,10 \\
\hline SMA & 2 & 10,52 \\
\hline Total & 19 & 100 \\
\hline
\end{tabular}

Tabel 4 Karakteristik responden berdasarkan perilaku hidup bersih dan sehat sebelum pemberian pendidikan kesehatan April 2014 di TPA Wonokromo

\begin{tabular}{|c|c|c|}
\hline $\begin{array}{c}\text { Batasan } \\
\text { Perilaku }\end{array}$ & Jumlah & $\begin{array}{c}\text { Prosentase } \\
(\boldsymbol{\%})\end{array}$ \\
\hline Baik & 0 & 0 \\
\hline Cukup & 8 & 42,10 \\
\hline Kurang & 11 & 57,89 \\
\hline Total & 19 & 100 \\
\hline
\end{tabular}

Tabel 5 Karakteristik responden berdasarkan perilaku hidup bersih dan sehat sesudah pemberian pendidikan kesehatan April 2014 di TPA Wonokromo

\begin{tabular}{|c|c|c|}
\hline $\begin{array}{c}\text { Batasan } \\
\text { Perilaku }\end{array}$ & Jumlah & $\begin{array}{c}\text { Prosentase } \\
(\mathbf{\%})\end{array}$ \\
\hline Baik & 14 & 73,68 \\
\hline Cukup & 5 & 26,31 \\
\hline Kurang & 0 & 0 \\
\hline Total & 19 & 100 \\
\hline
\end{tabular}

Tabel 6 Karakteristik responden berdasarkan perilaku hidup bersih dan sehat sebelum dan sesudah pemberian pendidikan kesehatan April 2014

\begin{tabular}{|c|c|c|c|c|}
\hline $\begin{array}{c}\text { Batasan } \\
\text { Perilaku }\end{array}$ & Pre & $(\%)$ & Post & $(\%)$ \\
\hline Baik & 0 & 0 & 14 & 73,68 \\
\hline Cukup & 8 & 42,10 & 5 & 26,31 \\
\hline Kurang & 11 & 57,89 & 0 & 0 \\
\hline Total & 19 & 100 & 19 & 100 \\
\hline \multicolumn{5}{|c|}{ Nilai p $=0,000$} \\
\hline
\end{tabular}

bersih dan sehat masing kurang. Perilaku Hidup Bersih dan Sehat (PHBS) itu sendiri merupakan semua perilaku kesehatan yang dilakukan atas kesadaran sehingga individu dan anggota keluarga dapat menolong dirinya 
sendiri di bidang kesehatan dan dapat berperan aktif dalam kegiatan-kegiatan kesehatan di masyarakat (Depkes RI, 2007). Perilaku kesehatan pada setiap individu pada dasarnya merupakan respon seseorang (organism) terhadap stimulus yang berkaitan dengan sakit dan penyakit, sistem pelayanan kesehatan, makanan, serta lingkungan (Simons-Morton et al.,1995). Perilaku hidup bersih dan sehat pada dasarnya sangat penting dalam kehidupan sehari-hari. Selama ini upaya yang dilakukan masyarakat untuk mengatasi masalah kesehatan (penyakit), masih banyak berorientasi pada penyembuhan penyakit, dimana apa yang dilakukan masyarakat dalam bidang kesehatan hanya untuk mengatasi penyakit yang telah terjadi atau menimpanya, di mana hal ini dirasa kurang efektif karena banyaknya pengeluaran. Upaya yang lebih efektif dalam mengatasi masalah kesehatan sebenarnya adalah dengan memelihara dan meningkatkan kesehatan serta mencegah penyakit dengan berperilaku hidup sehat, namun hal ini ternyata belum disadari dan dilakukan sepenuhnya oleh masyarakat (Kusumawati, 2004). Faktor-faktor yang mempengaruhi pengetahuan salah satunya ádalah pendidikan. Berdasarkan tabel 3 didapatkan sebagian besar pendidikan dari para responden adalah SMP berjumlah 8 orang $(42,10 \%)$ dan SD 6 orang $(31,57 \%)$, bahkan masih terdapat pula responden yang tidak sekolah sebanyak 3 orang $(15,78 \%)$. Hasil yang didapatkan setelah dilakukannya pendidikan kesehatan menunjukan bahwa rata-rata pendidikan dari para pemulung masih rendah. Menurut Mubarak et al, 2007 Pendidikan berarti bimbingan yang diberikan seseorang kepada orang lain terhadap sesuatu hal agar mereka dapat memahami. Tidak dapat dipungkiri bahwa makin tinggi pendidikan seseorang semakin mudah pula mereka menerima informasi, dan pada akhirnya makin banyak pula pengetahuan yang dimilikinya. Sebaliknya jika tingkat pendidikan seseorang rendah, akan menghambat perkembangan perilaku seseorang terhadap penerimaan, informasi dan nilai-nilai yang baru diperkenalkan. Pendidikan lebih menekankan pada pembentukan manusianya (penanaman sikap dan nilai-nilai). Pada tabel 1 sebagian besar pemulung yang bekerja di TPA Wonokromo berusia $>40$ tahun yaitu sebanyak 11 orang
(57,89\%). Pendidikan dan promosi kesehatan merupakan salah satu bentuk pendidikan orang dewasa (adult education). Pendidikan orang dewasa merupakan lanjutan atau pengganti pendidikan di sekolah atau universitas. Sasaran belajar adalah orang dewasa atau anggota masyarakat umum yang ingin mengembangkan pengetahuan, keterampilan, perilaku dan kemampuankemampuan lain. Hasil pendidikan orang dewasa adalah perubahan kemampuan, penampilan, atau perilaku. Selanjutnya, perubahan perilaku didasari adanya perubahan pengetahuan, sikap, dan keterampilan. Perubahan perilaku dalam proses pendidikan orang dewasa pada umumnya lebih sulit dibandingkan perubahan perilaku pada anak (pedagogik). Seperti diketahui bahwa orang dewasa mempunyai pengetahuan, sikap, dan perilaku yang mereka miliki selama bertahun-tahun sehingga perilaku baru yang belum mereka yakini menjadi sulit diterima (Notoadmodjo, 2003).

Dari pembahasan diatas dapat diambil kesimpulan salah satu faktor yang mengakibatkan kurangnya perilaku hidup bersih dan sehat pada para pemulung dikarenakan tingkat pendidikan formal mereka rata-rata masih rendah bahkan adapula yang sama sekali tidak mengikuti pendidikan formal sehingga pengetahuan yang mereka miliki tidak seberapa dikarenakan cara berpikir dan respon yang ambil belum sepenuhnya mereka dapatkan atau kuasai. Mereka belum bisa begitu memahami dan membedakan manakah kebiasaan yang baik untuk kesehatan dan manakah yang merugikan kesehatan dari pekerjaan yang mereka lakukan atau geluti selama bertahun-tahun. Karena kebiasaan ini sudah sering dilakukan sehingga mereka beranggapan bahwa apa yang mereka lakukan selama ini bukanlah masalah yang besar sehingga mereka tetap melakukannya. Untuk menerapkan perilaku PHBS pada pemulung diperlukan suatu perubahan sikap dari dalam diri sendiri. Kehidupan mereka yang selalu bergelut dengan sampah atau barang-barang bekas sangat beresiko untuk terpaparnya penyakit. Pendidikan yang kurang ditambah pengetahuan yang rendah memiliki pengaruh yang besar terhadap kehidupan sehari-hari dalam melakukan sesuatu atau mengambil suatu keputusan 
yang tepat. Di tambah pula dengan tidak adanya pendidikan kesehatan terhadap masyarakat membuat seseorang atau individu tidak memiliki informasi ataupun pengetahuan mengenai perilaku hidup bersih seperti halnya pada para pemulung. Rendahnya pendidikan formal dari para pemulung maka bisa dipastikan sebagian besar para pemulung belum mengerti benar mengenai cara hidup sehat yang baik yang berkaitan dengan pekerjaan mereka sehingga batasan perilaku hidup bersih dan sehat mereka berkisar cukup dan kurang sedangkan untuk individu yang berprilaku hidup bersih dan sehatnya yang baik belum ditemukan. Hal ini perlu ditangani karena bila dibiarkan resiko tepaparnya penyakit pada pemulung akan meningkat bahkan bisa menjadi hal yang lebih buruk lagi.

Berdasarkan tabel 5 terlihat bahwa dari 19 responden, 14 responden $(73,68 \%)$ berprilaku hidup bersih dan sehat yang baik.

Menurut Notoatmodjo, salah satu dasar orang berprilaku adalah dipengaruhi oleh pendidikan. Salah satu cara untuk menangani atau mengatasi perilaku hidup bersih dan sehat yang kurang yaitu melalui pendidikan kesehatan. Pendidikan kesehatan pada hakikatnya adalah suatu kegiatan atau usaha untuk menyampaikan pesan kesehatan pada masyarakat, kelompok, atau individu, dengan harapan bahwa dengan adanya pesan tersebut masyarakat, kelompok atau individu dapat memperoleh pengetahuan tentang kesehatan yang lebih baik (Soekidjo Notoatmodjo, 2007). Lebih dari itu, pendidikan kesehatan pada akhirnya bukan hanya mencapai kesehatan pada masyarakat saja, namun yang lebih penting adalah mencapai perilaku kesehatan (healthy behaviour). Kesehatan bukan hanya diketahui atau disadari (knowledge) dan disikapi (attitude), melainkan harus dikerjakan atau dilaksanakan dalam kehidupan sehari-hari (practice). Hal ini berarti bahwa tujuan akhir dari pendidikan kesehatan adalah agar masyarakat dapat mempraktekan hidup sehat bagi dirinya sendiri dan bagi masyarakat, atau masyakat dapat berperilaku hidup sehat (healthy life style) (Notoatmodjo, 2003).

Pada tabel 1 rata-rata usia para pemulung adalah dewasa tua yang dimana pengalaman hidup mereka sudah banyak dan bersamaan dengan itu pengetahuannya juga selalu bertambah karna pengetahuan tidak selamanya didapatkan melalui pendidikan formal, namun melalui pendidikan nonformal juga bisa, seperti membaca dari koran, media elektronik dan media masa lainnya. Menurut Sunaryo, 2004 semakin tinggi usia seseorang maka tingkat IQ juga semakin stabil. Dengan semakin tinggi usia seseorang atau semakin matang seorang individu pengalaman yang didapatpun semakin banyak dan dalam hal menerima suatu informasi lebih mudah dicerna untuk di pahami dan dimengerti. Berdasarkan tabel 3 dapat dilihat sebagian besar pemulung pernah menempuh pendidikan formal. Dari 19 responden 16 diantaranya pernah menempuh pendidikan formal walaupun dengan tingkat pendidikan yang berbeda-beda sehingga dalam pemberian informasi mereka lebih mudah menerima, mencerna atau merespon karena sudah memiliki pengalaman dibandingkan mereka yang tidak pernah menempuh pendidikan formal. Peran pendidikan kesehatan dilingkungan atau masyarakat memang sangat penting bagi individu, kelompok ataupun komunitas dan sebagainya, karena masyarakat masih banyak yang kurang mengerti akan dampak dari pendidikan kesehatan tersebut, yang tentunya pendidikan kesehatan akan meningkatkan status kesehatan yang ada pada lingkungan tersebut. Dengan adanya pendidikan kesehatan maka kita sudah menciptakan suatu usaha untuk menyediakan psikologis dan sasaran agar mereka berprilaku sesuai dengan tuntutan nilai-nilai kesehatan. Oleh sebab itu pendidikan kesehatan harus diterapkan pada para pemulung sehingga mereka lebih mengetahui dan memahami informasi mengenai kesehatan terutama perilaku hidup bersih dan sehat.

Berdasarkan tabel 6 jumlah responden sebelum dilakukan pendidikan kesehatan yang berperilaku hidup bersih dan sehat dengan kriteria baik tidak didapatkan $(0 \%)$ dan responden yang berperilaku hidup bersih dan sehat setelah dilakukan pendidikan kesehatan dengan kriteria baik sebanyak 14 responden $(73,68 \%)$. Hasil uji statistic wilcoxon pengaruh pendidikan kesehatan terhadap perilaku hidup bersih dan sehat pada pemulung didapatkan hasil $\mathrm{p}=0.000$ yang berarti $\mathrm{p}<0.05$ dengan demikian Ho ditolak dan H1 diterima yang memiliki arti ada pengaruh pendidikan kesehatan terhadap perilaku hidup bersih dan 
sehat pada pemulung di TPA WonokromoSurabaya.

Salah satu faktor yang mempengaruhi perilaku adalah pengetahuan (knowledge). Pengetahuan adalah hasil penginderaan manusia atau hasil tahu seseorang terhadap objek melalui indera yang dimilikinya (mata, hidung, telinga). Dengan sendirinya, pada waktu penginderaan sampai menghasilkan pengetahuan tersebut sangat dipengaruhi oleh intensitas perhatian dan persepsi terhadap objek. Komponen kognitif merupakan representasi yang dipercaya oleh individu. Komponen kognitif berisi persepsi dan kepercayaan yang dimiliki individu mengenai sesuatu kepercayaan datang dari yang telah dilihat, kemudian terbentuk suatu ide atau gagasan mengenai sifat atau karakteristik umum suatu objek. Sekali kepercayaan telah terbentuk, akan menjadi dasar pengetahuan seseorang mengenai yang dapat diharapkan dari objek tertentu. Menurut Green, 1980, pendidikan kesehatan mempunyai peranan penting dalam mengubah dan menguatkan faktor perilaku (predisposisi, pendukung dan pendorong) sehingga menimbulkan perilaku positif dari masyarakat. Hal ini menunjukan bahwa perilaku, pendidikan kesehatan dan status kesehatan masyarakat berada dalam suatu pola hubungan yang saling mempengaruhi.

Dengan diberikannya pendidikan kesehatan pada pemulung perubahan yang mereka lakukan cukup besar yakni dari yang sebelumnya tidak ada satupun yang berperilaku hidup bersih dan sehat, namun setelah diberikan pendidikan kesehatan didapatkan beberapa orang yang mengalami perubahan pola pikir menjadi lebih baik. yang baik secara tidak langsung kita secara perlahan ingin mengubah perilaku mereka dari yang negatif kearah yang lebih positif khususnya yang berkaitan dengan perilaku hidup bersih dan sehat mereka, sehingga kemampuan dan kemauan hidup sehat bagi setiap penduduk tercipta agar dapat mewujudkan derajat kesehatan yang optimal. Dengan perkataan lain mereka (pemulung) diharapkan mampu berpartisipasi aktif dalam memelihara dan meningkatkan derajat kesehatannya sendiri, dengan demikian masyarakat mampu menjadi subjek dalam pembangunan kesehatan.

\section{Kesimpulan}

Berdasarkan hasil penelitian yang berprilaku hidup bersih dan sehat sebelum pendidikan kesehatan dengan kriteria kurang sebanyak 11 orang $(57,89 \%)$ dan setelah pendidikan kesehatan dengan kriteria baik sebanyak 14 responden $(73,68 \%)$. Ada pengaruh pendidikan kesehatan terhadap perilaku hidup bersih dan sehat pada pemulung di TPA Wonokromo-Surabaya yang dibuktikan dengan uji statistik wilcoxon dengan nilai $\mathrm{p}=0.000$.

\section{DAFTAR PUSTAKA}

Ainur. 2012. Tatanan PHBS. http://arnisyalifeyanis.blogspot.com/2013/06/tatananPHBS.html. Diakses tanggal 21 November 2013 Pukul 20.00 wib.

Azis. 2009. Konsep Sampah dan Pemulung. http://purwantoazis.blogspot.com/20 10/05/Konsep-sampah-danpemulung. Diakses tanggal 19 November 2013 Pukul 14.00

Bagus. 2011. Perilaku Hidup Bersih dan Sehat: http://suka2bayu.blogspot.com/2011/11/perilakuhidup-bersih-

sehat.html.diunduhtanggal 15 April 2014 pukul 15.30

Budiono. 2011. PHBS dalam lingkup Pemulung.

http://belajarpsikologi.com/PHBSdalam-lingkup-pemulung. Diakses tanggal 29 November 2013. Jam 19.00

Chandra Budiman. (2007). Pengantar Kesehatan Lingkungan. Jakarta : EGC

Departemen Kesehatan RI. (2010). PHBS 10 Indikator pada Tatanan Rumah Tangga. Jakarta : Depkes RI

Green. 1980. Promosi Kesehatan dan Ilmu Perilaku dikutip dalam buku Notoatmodjo. Jakarta : Rineka Cipta 
Kementrian Kesehatan RI. (2011). Pedoman Pembinaan Perilaku Hidup Bersih dan Sehat (PHBS). Http:www.promkes.depkes.go.id/ind ex.php/mediaroom/pedoman-danbuku?download=28:phbs. Diakses 5 November 2013 pukul 16.00

Herawani. (2002). Pendidikan Kesehatan Dalam Keperawatan. Jakarta : EGC.

Mubarak Iqbal Wahit. (2012). Ilmu Kesehatan Masyarakat. Jakarta : Salemba Medika.

Notoatmodjo Soekidjo. 1997. Ilmu Kesehatan Masyarakat PrinsipPrinsip Dasar. Jakarta : Rineka Cipta.

(2007). Kesehatan Masyarakat Ilmu dan Seni. Jakarta : Rineka Cipta.

Penelitian Kesehatan. Jakarta: PT Rineka Cipta

Nursalam. 2003. Konsep dan Penerapan Metodologi Penelitian Ilmu Keperawatan: Pedoman Skripsi, Tesis dan InstrumenPenelitian. Jakarta: Salemba Medika

Setiadi. 2007. Konsep Penulisan Riset Keperawatan. Yogyakarta: Graham Ilmu

Sunaryo. 2004. Psikologi Perkembangan. Jakarta: Rosda Karya

Simons-Morton. 1995. Perilaku Kesehatan dikutip dalam buku Notoatmodjo. Jakarta : Rineka Cipta

Yamin, Sofyan. 2009. SPSS Complete Teknik Analisis Statistik Terlengkap dengan Software SPSS. Edisi 2. Jakarta: Salemba Infotek 